\title{
Introducing Velocity Index for Water Distribution Systems
}

\author{
$\underline{\text { Savalan Pour Akbarkhiavi }}{ }^{a}$, Monzur Alam Imteaz ${ }^{\text {a }}$ and Pathmanathan Rajeev ${ }^{\text {a }}$ \\ a Department of Civil and Construction Engineering, Swinburne University of Technology, \\ Melbourne, VIC 3122, Australia, \\ Email: spourakbarkhiavi@swin.edu.au
}

\begin{abstract}
Planning and hydraulic modelling phase in Water Distribution Systems (WDS) are playing an enormous role for water authorities. Making wise decisions in planning phase will ease the future recurrent budget for Capital Expenditures (Capex) and Operating Expense (Opex) to guarantee achieving the acceptable quality of service in WDS encountering population growth and land developments. The conventional methodology for planning of WDS includes the population growth impact assessment on the system and then proposing new assets to comply with the local water distribution code. Potable water networks need asset planning, augmentation strategies and rehabilitation schemes in consistence with the new assigned loads to them. Planning strategies are usually based on sophisticated hydraulic models and a determined and pre-defined time intervals to maintain the level of service after occurrences of increase in design serviced population, asset ageing and/or serviced area. Systems rehabilitation studies require significant amount of budget which is the main constraint for the water authorities for the implementation of any augmentation plan.
\end{abstract}

Two main factors are playing roles in WDS asset planning strategies. The first parameter is the acceptable Level of Service and the second factor is the "Associated Cost" of the asset planning. The main goal of a proper planning in a WDS is the prediction of a system's behavior in future and suggestion of efficient set of solutions for the predicted demand. The most critical criteria to be addressed and augmented in a typical urban WDS are water pressures and water velocities. Water pressure is the first tangible measure that customers feel and the water velocity has impact on energy loss in the system which is an indicator of applied shear stress from water to inner side of the pipes. The water pressure and the water velocity are two main hydraulic factors which are affected by population growth and therefore capital expenditure needed to rectify them.

Authors earlier introduced a Pressure Index (PI) for WDS and studied the relationship between PI improvements and augmentation costs per connection. Authors' earlier publication considered the modification and improvement of pressures in the water systems. In the current paper, development and calibration of further hydraulic models (using Innovyze InfoWorks WS model) for water systems are presented. In addition to the introduced PI factors, in this paper a new index (Velocity Index, VI) is introduced for the assessment of WDS from the water velocity point of view. Relationships between improvements of Level of Service (considering VI) and "Associated Cost" in WDS are presented.

Keywords: Level of service, network planning, velocity index, upgrade cost, water distribution system 


\section{INTRODUCTION}

These days, cities, townships and other inhabited areas around the world are facing considerable problems to manage urban development and population growth. Under such conditions an appropriate Water Distribution System (WDS) planning is playing a crucial role to improve the effectiveness of the investments that are taken place in the urban water systems. A proper water asset planning should include a comprehensive and rigorous identification of all options to meet the defined service levels, including options based on non-asset solutions. Planning should be an iterative process which attempts to balance service needs with infrastructure, operation and maintenance, financial and environmental options.

The most expensive element of a water supply system is the distribution network. Deficiency in distribution network due to aging and stress will cause great operation and maintenance costs, water leakage, decrease in the quality of service, and drop in the quality of water supply. (Kleiner et al., 1998). Effective WDS planning outcomes can only result from rigorous analysis, the application of strategic thinking skills and the adoption of an integrated approach to urban water planning which considers, where appropriate, water supply, sewerage and management of stormwater as a single system. (DSEWPC, 2015)

A planning guidelines for water supply and sewerage document by Department of Energy and Water Supply of Queensland government in Australia has shown the greatest opportunity to influence project outcomes, minimise risk and reduce costs exists in the early stage of an initiative (i.e. during the planning stage) as illustrated in Figure 1. Investment in planning, while often incorrectly seen to be a significant cost, has the potential to result in substantial dividends (financial and non-financial). The cost of planning in comparison to the capital expenditure involved in infrastructure construction and on-going operation and maintenance is low.

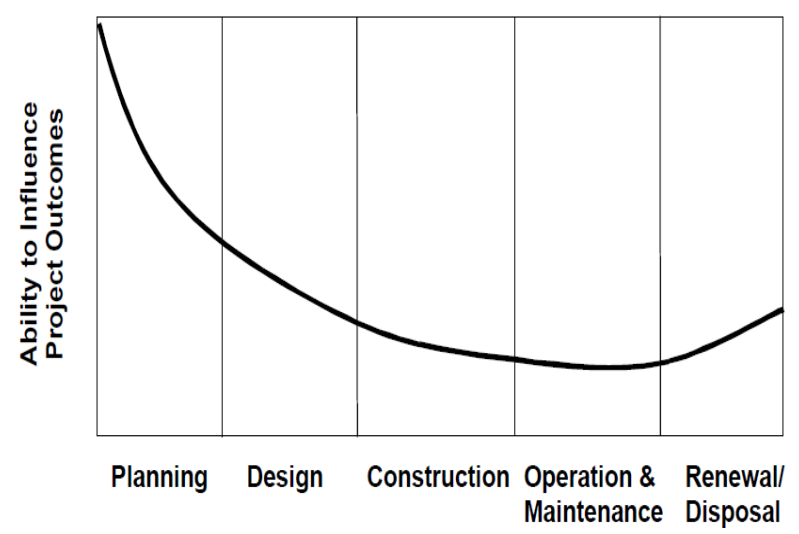

Figure 1. Ability to influence project outcomes.

Current common approach for WDS asset planning is utilizing advanced and sophisticated hydraulic models (Bush, C.A., and Uber, J.G 1998) and it has been proven that these models can be used for planning purposes by simulating the existing assets and applying future scenario demands. (Alperovits and Shamir, 1977)

There are some issues involved in using of hydraulic models such as:

- Necessity in understanding of complicated hydraulic concepts related to water networks;

- Spending significant amount of time and resource for establishing the existing and future scenarios ; and

- The notable market price of existing hydraulic model platforms

As a conclusion, a successful network modelling requires the investment of time by experienced staff to interpret the results of the modeling. Model outputs should be verified against actual system performance and be calibrated based on the monitored flow, pressures, tank levels and etc. The whole process is costly and time consuming for the responsible water authority. The main aim of water system's upgrade is maintaining the acceptable level of service after increase in serviced population/area and asset ageing. It is obvious that system upgrades are constrained by budget allocation; and every upgrade is a cost-intensive and demanding exercise. (Alonso, et al., 2000). Therefore, from one side the critical customer-oriented parameter is Level of Service and from the other side the critical factor is "Upgrade Cost". (Eiger, et al., 1994)

Till now very limited researches have been conducted to study the relationship between maintaining the accepted Level of Service and associated "Upgrade Cost". Currently there is no standard factor and/or index to compare a particular upgrade option with another potential option from the level of service perspective.

\section{METHODOLOGY}

The primary objective of this research is the development of a tool to identify the relationship between level of service of WDS and the cost of essential water asset upgrade to be in an acceptable level of service range. To cover the above aims, a new factor in water distribution systems has been defined to address the existing gap in evaluation of Level of Service in a WDS. A survey has been conducted among number of Victorian 
water authorities to get their opinions about proposed factor and the weightage parameters in the proposed factor.

Three Victorian townships as case study of existing WDS have been examined for the new defined factor. Advanced hydraulic models have been built and utilized to simulate the case study WDS. InfoWorks WS has been used in this research as the main modeling and calibration platform for models. All models were calibrated against the monitored pick flow for systems pressures, velocities and tank levels. An approved population projection applied to the built and calibrated models in 4 planning target years. The base model were built on 2010 population statistic and forecasted population for year 2013 were used in building of the first study model. Years 2018 and 2023 have considered for staging process and year 2033 have been targeted as the ultimate planning year. These years are consistent with Victorian Water Plan 3, 4 and 5.

\section{STUDY AREA}

As a case study, the water supply system of three townships in the vicinity of Castlemaine, Victoria, Australia have been studied. The water system in the comprehensive Castlemaine water supply system includes the townships of Castlemaine, Chewton, Campbells Creek, Fryerstown, Guildford, Yapeen, Harcourt, Maldon and Newstead. Figure 2 shows the locality of the case study area.

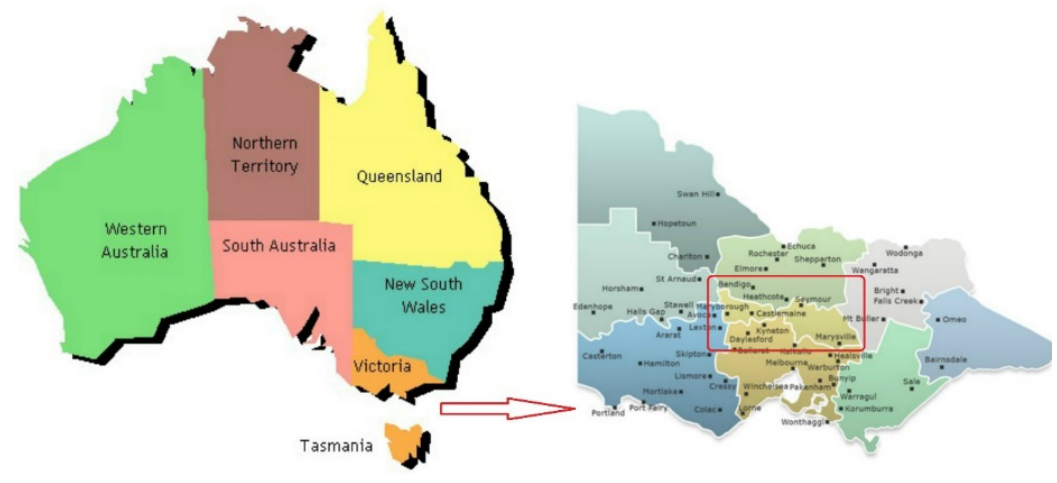

Figure 2. Locality of the study area.

The studied system serves a population of 13,350 residents as well as commercial and industrial customers. Approximately 7,050 properties are connected to the system.

The focus of this paper is on the following three systems in the comprehensive Castlemaine WDS area:

- The Eureka System

- The Fryerstown System

- The Maldon System

All three studied townships has shown a steady growth over the last decade and are expected to have continues mild growth based on the studied population projection by the responsible water authority.

\section{DATA}

The 2010 demands defined by the water authority were used and allocated in the developed InfoWorks WS baseline model peak day scenario as the baseline. The increase in residential demand for each planning stage has been calculated based on the projected total number of additional residential connections.

Based on the respective water authority's approved demand, the adopted peak day residential demands were:

- $1,825 \mathrm{~L} /$ Connection/day for urban areas

- $2,320 \mathrm{~L} /$ Connection /day for small towns

The general approach to developing solutions for the Castlemaine upgrade strategy for the purpose of this research was to ensure that the system could satisfactorily meet the minimum levels of service and satisfy forecasts for current and future demand whilst achieving adequate security of supply for all areas. This has involved amplifying ageing and overly stressed pipes to reduce headloss to acceptable levels and improve pressures in the downstream areas, and upsizing existing storages where they were reckoned to be undersized 
based on future growth in demand. Where pipe amplifications were deemed inadequate to maintain $>20 \mathrm{~m}$ pressure, options to re-zone problem areas or re-configure supply to enable feed from a higher grade system have been considered.

\section{INTRODUCING NEW INDEXES FOR WDS}

In this paper a new indexes have been defined as one of the main control factors in WDS planning. The new index reveals the water distribution systems status from the pipe velocities perspective and is called Velocity Index (VI). The VI defined in the way that the lengthier pipe with very high velocities has the greater impact on the VI.

The proposed formula for the VI is:

$$
\mathrm{VI}=\frac{\mathrm{LT}}{K \cdot \sum_{\mathrm{i}=1}^{\mathrm{n}}\left[\frac{\mathrm{LPi}}{\mathrm{LT}} *|\mathrm{Vmax}|-\mathrm{Vmax}_{-} \mathrm{acc}\right]+\mathrm{LT}}
$$

Where:

- LT: Total lengths of pipes in the system $(\mathrm{km})$

- LPi: Length of each assessed pipe

- Vmax_acc: The maximum acceptable velocity of the pipe by the authority

- Vmax: Maximum velocity of the assessed pipe if it's greater than Vmax_acc

- $\mathrm{K}$ : Authority weight factor

The VI index has been defined to comply with Water Services Association of Australia (WSAA) code which is widely used throughout Australia as the main planning code for WDS. Therefor the maximum acceptable velocity of the pipe (Vmax_acc) has been considered $2 \mathrm{~m} / \mathrm{s}$ to be consistent with the current practice. K factor indicates the importance of high velocities in the system from respective asset planning authority. $\mathrm{K}$ has been assigned as 1 based on the discussion with the water authority. With the mentioned figures the proposed VI formula is:

$$
\mathrm{VI}=\frac{\mathrm{LT}}{1 . \sum_{\mathrm{i}=1}^{\mathrm{n}}\left[\frac{\mathrm{LPi}}{\mathrm{LT}} *|\mathrm{Vmax}|-2\right]+\mathrm{LT}}
$$

The VI value have been calculated for studied water pressure zone once before asset planning and once after assigning the optimum augmentation strategy. Then the improvements of VI have been monitored and trended. Approved asset planning and augmentation strategies were applied to the networks to simulate the future increased populations and demands. Each anticipated asset planning required certain amount of cost. Eventually, relationships of estimated asset planning costs with the improved "VIs" were presented. Relationships obtained are discussed in details in regards WDSs improvement in Level of Service and effectiveness of proposed asset planning scheme.

\section{RESULTS AND DISCUSSION}

The VI has been calculated for Eureka, Fryerstown and Maldon pressure zones for approved demands for planning target years of 2013, 2018, 2023 and 2038 in two following scenarios:

- Without water network upgrade

- With approved water network upgrade

Table 1 and Graph 1 show the overview of the modelled WDS in three case study townships along with the number of water connections per each townships. The number of connections per township has been received from the responsible water authority (Coliban Water). The VI has been calculated for the three case study townships to assess the impact new demands on the water systems without applying any upgrades. As shown in the Eureka water network the VI drops from 0.25 to 0.11 in 2013 and 2038 respectively. The decrease in VI is occurring in the Fryerstown system with steeper rate from 0.32 to 0.14 which suggests the sensitivity of the smaller systems to population growth. The same decreasing pattern is shown in Maldon water system from 0.28 to 0.22 in the same period. However the VI shows less dropping rate in the system with largest number of connections. All three water systems show the notable increase in VI after applying the approved network upgrade works. The VI stays in the range of $0.65-0.72$ after upgrade works which suggests the acceptable range of VI from water authority's point of view. 
Pour Akbarkhiavi et al., Introducing Velocity Index for Water Distribution Systems

Table 1. InfoWorks hydraulic model results overview for case study townships.

\begin{tabular}{|c|c|c|c|c|c|c|c|c|c|}
\cline { 3 - 9 } \multicolumn{2}{c|}{} & \multicolumn{3}{c|}{$\begin{array}{c}\text { Calculated VI with no } \\
\text { Network Upgrade }\end{array}$} & \multicolumn{3}{c|}{$\begin{array}{c}\text { Calculated VI with Network } \\
\text { Upgrade }\end{array}$} \\
\cline { 2 - 11 } & $\begin{array}{c}\text { Number of } \\
\text { connections }\end{array}$ & 2013 & 2018 & 2023 & 2038 & 2013 & 2018 & 2023 & 2038 \\
\cline { 2 - 11 } & 638 & 0.25 & 0.22 & 0.18 & 0.11 & 0.69 & 0.67 & 0.67 & 0.66 \\
\hline Eureka & 99 & 0.32 & 0.25 & 0.19 & 0.14 & 0.71 & 0.69 & 0.68 & 0.65 \\
\hline Fryerstown & 1016 & 0.28 & 0.26 & 0.23 & 0.22 & 0.72 & 0.70 & 0.69 & 0.67 \\
\hline
\end{tabular}

Graph 1. The VI variations in Eureka, Fryerstown and Maldon before and after water network upgrades
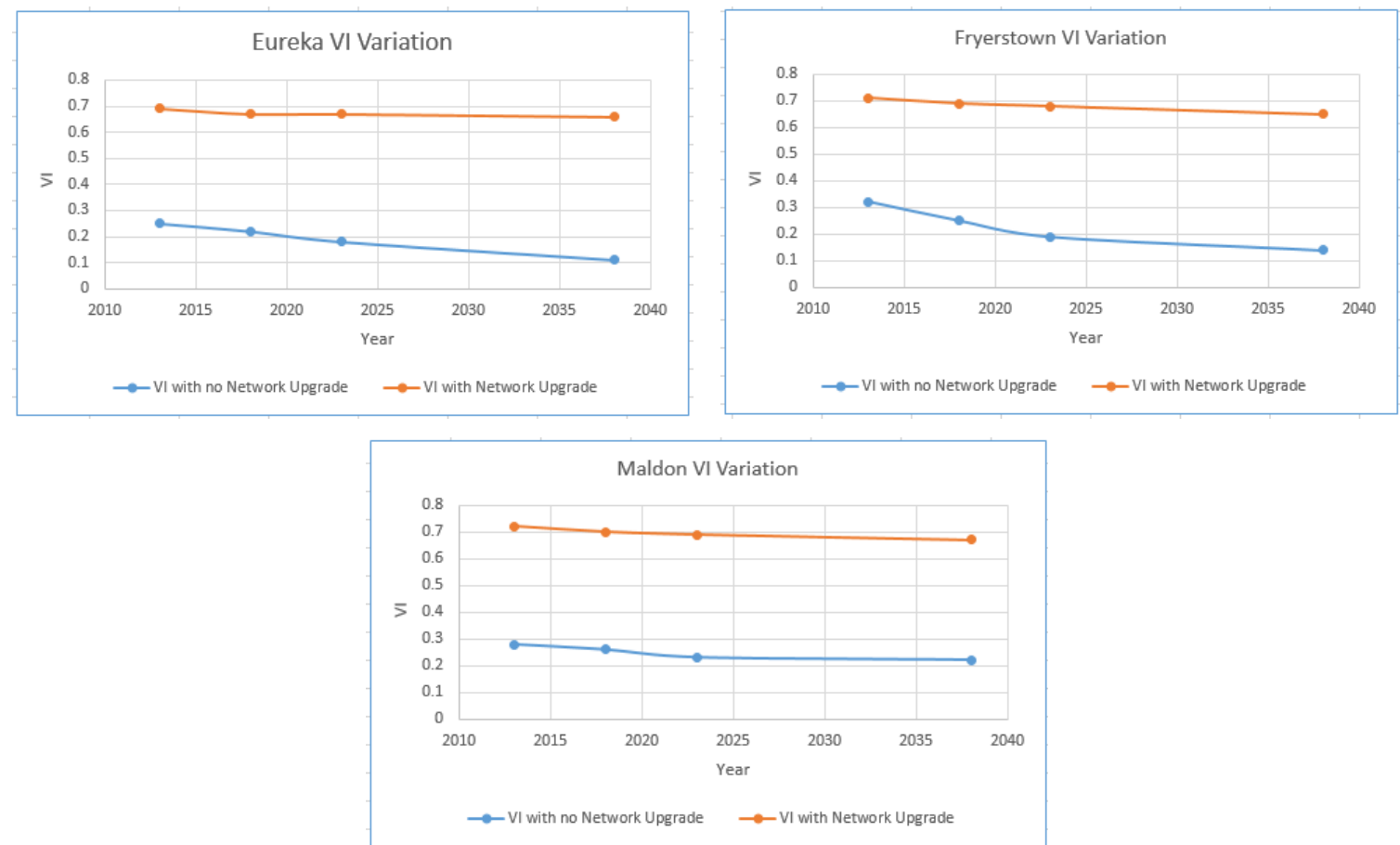

By comparison between VI figures for each town in studied planning years before and after network upgrade works, the VI Variation or $\Delta$ VI can be calculated. This term is a useful figure to show the effectiveness of the planned upgrade works. This also is an indicator of the extent of the needed upgrade works in every planning year. Table 2 shows the variation in VI for each town in target years before and after the network upgrade works.

Table 2. The VI variation $(\Delta \mathrm{VI})$ for case study townships for planning each year target.

\begin{tabular}{|c|c|c|c|c|}
\cline { 2 - 5 } \multicolumn{1}{c|}{} & \multicolumn{4}{c|}{ VI Variation - $\Delta$ VI } \\
\cline { 2 - 5 } \multicolumn{1}{c|}{} & $\mathbf{2 0 1 3}$ & $\mathbf{2 0 1 8}$ & $\mathbf{2 0 2 3}$ & $\mathbf{2 0 3 8}$ \\
\hline Eureka & 0.44 & 0.45 & 0.49 & 0.55 \\
\hline Fryerstown & 0.39 & 0.44 & 0.49 & 0.51 \\
\hline Maldon & 0.44 & 0.44 & 0.46 & 0.45 \\
\hline
\end{tabular}

Table 3 shows the associated cost of approved network upgrade works for case study townships per each planning target year. This information has been received from Coliban Water which is the responsible water authority for asset planning in the study area. The approved upgrade works were pipe replacement, pipe duplication, new Pressure Reducing Valve (PRV) installation and network rezoning. The cost estimation 
were based on the database of Coliban Water from current upgrade works and the last 5 years of augmentation cost.

Table 3. The associated upgrade cost for case study townships for each planning year target.

\begin{tabular}{|c|c|c|c|c|}
\cline { 2 - 5 } \multicolumn{1}{c|}{} & \multicolumn{4}{c|}{ Associated Upgrade Cost (AUD) } \\
\cline { 2 - 5 } \multicolumn{1}{c|}{} & $\mathbf{2 0 1 3}$ & $\mathbf{2 0 1 8}$ & $\mathbf{2 0 2 3}$ & $\mathbf{2 0 3 8}$ \\
\hline Eureka & 662000 & 667500 & 672500 & 677600 \\
\hline Fryerstown & 97000 & 102150 & 104000 & 105000 \\
\hline Maldon & 1040000 & 1045000 & 1050000 & 1058500 \\
\hline
\end{tabular}

By dividing the associated cost of approved network upgrade works for case study townships by the townships number of connections the cost per connection figure can be calculated. As expected for each town the cost per connection has an increasing trend between 2013 and 2038. Table 4 presents the system upgrade cost per connection figure per connection.

Table 4. The associated upgrade cost per connection for each planning year target.

\begin{tabular}{|c|c|c|c|c|}
\cline { 2 - 5 } \multicolumn{1}{c|}{} & \multicolumn{4}{c|}{ Upgrade Cost per Connection (AUD) } \\
\cline { 2 - 5 } \multicolumn{1}{c|}{} & $\mathbf{2 0 1 3}$ & $\mathbf{2 0 1 8}$ & $\mathbf{2 0 2 3}$ & $\mathbf{2 0 3 8}$ \\
\hline Eureka & 1038 & 1046 & 1054 & 1062 \\
\hline Fryerstown & 980 & 1032 & 1051 & 1061 \\
\hline Maldon & 1024 & 1029 & 1033 & 1042 \\
\hline
\end{tabular}

If the figures for $\Delta \mathrm{VI}$ (Table 2) are likened to the related water system upgrade cost per connection (Table 4), a relationship between improvement in VI and its associated cost can be identified. Table 5 and Graph 1 show the relationship between $\Delta \mathrm{VI}$ and the associated cost. Table 5 and Graph 2 present the needed budget to achieve this improvement in the VI. The cost in the range $(980-1062)$ AUD per connection seems to be the expenditure that causes the improvement in the VI in the range of $(0.39-0.55)$

Table 5. and Graph 2. The associated upgrade cost per connection for respective VI improvement.

\begin{tabular}{|c|c|}
\hline$\Delta \mathrm{VI}$ & $\begin{array}{c}\text { Upgrade Cost per } \\
\text { Connection (AUD) }\end{array}$ \\
\hline 0.39 & 980 \\
\hline 0.44 & 1024 \\
\hline 0.44 & 1029 \\
\hline 0.44 & 1032 \\
\hline 0.44 & 1038 \\
\hline 0.45 & 1042 \\
\hline 0.45 & 1046 \\
\hline 0.46 & 1048 \\
\hline 0.49 & 1051 \\
\hline 0.49 & 1054 \\
\hline 0.51 & 1061 \\
\hline 0.55 & 1062 \\
\hline
\end{tabular}

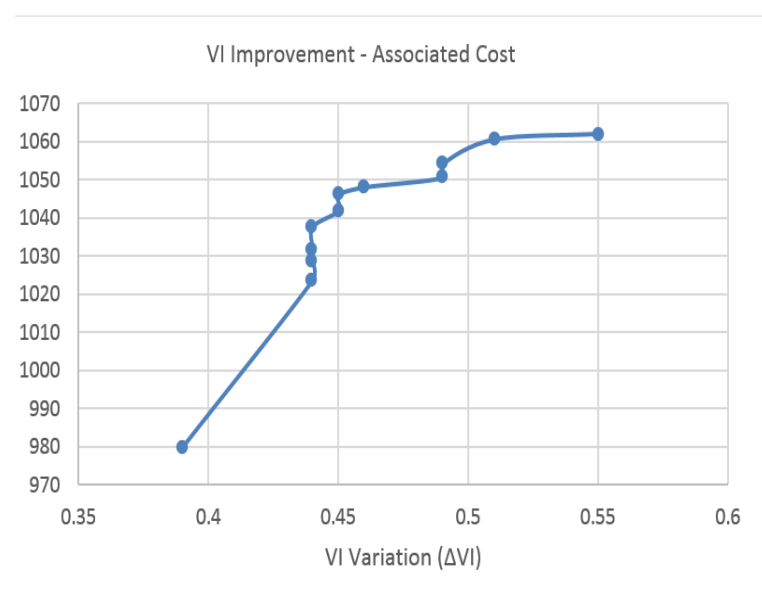




\section{CONCLUSIONS}

Water networks upgrading and augmentations require significant budget allocation, which is one of the main concerns of the water authorities for the implementation of water systems upgrade planning. So far the undertaken researches in the field of water network planning predominantly have been focused on optimization of proposed upgrade works.

In this paper, a new index has been introduced to evaluate the level of service of water distribution systems from pipe velocities point of view. The index has been named as "Velocity Index" (VI) since it targets the evaluation of WDS level of service based on occurring pipe velocities in the system in current and future populations. This study was done for three Australian townships in Castlemaine WDS area as a case study. An InfoWorks WS hydraulic model were developed for four planning target years of 2013, 2018, 2023 and 2038. The first three planning target years were adopted as the staging target and the year 2038 were chosen as the ultimate planning target year. The information about the water demands forecast, approved upgrade strategy and the cost estimation were received from Coliban Water which is the responsible water authority for asset planning in the research area.

The research has shown that the VI factor drops by demand increase in the case study townships and by applying the approved upgrade works, the VI factor rises to the range of $(0.65-0.72)$. This range seems to be the minimum VI for an acceptable level of service provided by approved upgrade strategy. It is found that in the case study townships; the budget in the range of $(\$ 1042$ - \$1062) per water connection is needed for the ultimate planning target year (2038) as upgrade cost to achieve the VI in the minimum acceptable range. The research identified that in the case study townships there is a meaningful trend between VI Variation $(\Delta \mathrm{VI})$ and the associated water network upgrade cost. $\Delta \mathrm{VI}$ is in the range of $(0.39-0.55)$ where the budget in the range of $(980-1062)$ AUD is needed to make the mentioned improvement in the VI.

\section{REFERENCES}

Kleiner Y., B. J Adams, and J. S Rogers, Long-term Planning Methodology for Water Distribution System Rehabilitation, Water Resources Research, 34(8), pp. 2039-2051, Aug. 1998.

DSEWPC website, Australian National principles for urban water planning. 2015.

Bush, C.A., and Uber, J.G., "Sampling Design Methods for Water Distribution Model Calibration", J. of Water Res. Plan. And Man., ASCE, 124(6) ,334- 344, 1998.

Alperovits, E., and Shamir, U., "Design of Optimal Water Distribution System” Water Resources Research, 13: 885-900, 1977.

Alonso, J. M., Alvarruiz, F., Guerrero, D., Hernández, V., Ruiz, P. A., Vidal, A. M., Martínez, F., Vercher, J., and Ulanicki, B. "Parallel computing in water network analysis and leakage minimization." Journal of Water Resources Planning and Management, 126(4), 251-260. 2000.

Eiger, G., Shamir, U., and Be-Tal, A., “Optimal Design of Water Distribution Networks.” Water Resour. Res., 30(9), 2637-2646, 1994. 